\title{
Erratum to: Development and Validation of a Clinical Prediction Rule of the Return-to-Work Status of Injured Employees in Minnesota
}

\author{
A. Bentley Hankins ${ }^{1} \cdot$ Christine A. Reid ${ }^{2}$
}

Published online: 7 August 2015

(c) Springer Science+Business Media New York 2015

\section{Erratum to: J Occup Rehabil \\ DOI 10.1007/s10926-015-9568-3}

Unfortunately, the return-to-work (RTW) rates for the binary variable attorney involvement in Table 1 are mistakenly transposed in the original publication of the article.

The correct RTW rates are $41.8 \%$ for injured employees with an attorney involved and $86.8 \%$ for injured employees with no attorney involved in their workers' compensation claim. The corrected portion of Table 1 is given below:

\begin{tabular}{llll}
\hline Variable & $\mathrm{n}$ & $\%$ & RTW \% \\
\hline Attorney involvement & & & \\
Attorney involved & 8,376 & 54.5 & 41.8 \\
No attorney involved & 6,996 & 45.5 & 86.8 \\
\hline
\end{tabular}

The online version of the original article can be found under doi:10.1007/s10926-015-9568-3.

\footnotetext{
A. Bentley Hankins

abhankins@hankinsvoccon.com

1 Hankins and Hankins Vocational Consulting, 115 West Main Street, Jonesborough, TN 37659, USA

2 Department of Rehabilitation Counseling, School of Allied Health Professions, Virginia Commonwealth University, P.O. Box 980330, Richmond, VA 23298, USA
} 